\title{
A Novel Mandibular Advancement Device for Treatment of Sleep-Disordered Breathing: Evaluation of Its Biomechanical Effects Using Finite Element Analysis
}

\author{
Jonghun Yoon ${ }^{1}$, Sang Hwa Lee ${ }^{2}$, Yuhyeong Jeong ${ }^{3}$, Dong-Hyun Kim ${ }^{4, *} \mathbb{C}$, Hyun-Il Shin ${ }^{4}$ and \\ So Yun $\operatorname{Lim}^{4}$ \\ 1 Department of Mechanical Engineering, Hanyang University, 55 Hanyangdaehak-ro, Sangnok-gu, Ansan-si, \\ Gyeonggi-do 15588, Korea; yooncsmd@gmail.com \\ 2 Department of Dentistry, Eunpyeong St. Mary's Hospital, College of medicine, the Catholic University of \\ Korea, 1021 Tongil-ro, Eunpyeong-gu, Seoul 03312, Korea; justina@catholic.ac.kr \\ 3 Department of Mechanical Design Engineering, Hanyang University, 222 Wangsimni-ro, Seongdong-gu, \\ Seoul 04763, Korea; jtpye9402@gmail.com \\ 4 Department of Otorhinolaryngology-Head and Neck Surgery, Incheon St. Mary's Hospital, College of \\ medicine, the Catholic University of Korea, Incheon 21431, Korea; marine_shs@naver.com (H.-I.S.); \\ lsy_stella@icloud.com (S.Y.L.) \\ * Correspondence: monolithkim@catholic.ac.kr; Tel.: +82-32-280-5151
}

Received: 2 June 2020; Accepted: 24 June 2020; Published: 27 June 2020

\begin{abstract}
Stress or pressure induced by the use of a mandibular advancement device (MAD) to treat sleep-disordered breathing can cause side effects including occlusal changes, pain, and discomfort. In this paper, we describe and use finite element (FE) analysis to evaluate a novel MAD that can reduce the stress and side effects associated with these devices. The MAD includes a protruding part that enables rostral movement of the lower tray, providing a wider upper airway and a supporting shield that helps uniformly distribute the concentrated stress. After assembling the three-dimensional model for the MAD and the upper oral structures, a designated force was applied to evaluate the stress distributions of a conventional MAD and the proposed design. FE analysis showed that the stress applied to the upper front teeth and the gingival area near the upper incisors differed between the newly developed and conventional MAD. Concentrated stress was relieved by inserting such a shield, helping to distribute the stress from the front teeth to the gingival area. Our proposed MAD reduced the concentrated stress on the front teeth by distributing it over the gingival area.
\end{abstract}

Keywords: finite element analysis; mandibular advancement device; sleep-disordered breathing

\section{Introduction}

Sleep-disordered breathing (SDB), including snoring and sleep apnea, tends to be induced by narrow upper airways and collapse of the throat. It results in daytime sleepiness, neurocognitive impairment, cardiovascular and metabolic disorders, and severe functional impairment that can even cause traffic accidents [1,2]. Although continuous positive airway pressure (CPAP) therapy devices are highly effective for treating SDB by utilizing air pressure to maintain the upper airway, there are several issues such as adaptation and compliance problems as well as the risk of iatrogenic pneumothorax [3]. A mandibular advancement device (MAD) is a superior alternative to CPAPs for patients suffering from SDB because they mainly act by expanding the upper airway. MADs push the mandible forward, which pulls up the oropharyngeal wall and keeps the airway open, thereby making breathing easier while 
asleep. Cephalometric and radiographic analysis revealed that the retropharyngeal air space increased after MAD use [4].MADs are also effective in increasing the tension around the oropharyngeal area, which reduces its collapsibility [5,6]. MADs are simple, easy to use, and convenient because they do not require surgery and thus eliminate the need to control postoperative pain and surgical side effects. However, the patient must wear the MAD every night to reduce the symptoms of SDB. According to previous studies $[3,7,8]$, pain in the teeth and gingiva is one of the main factors in patient unwillingness to continue using an MAD. In addition, one of the most important side effects of MAD use are occlusal change following long-term treatment [9-11]. Therefore, to improve patient compliance, it is important to design an MAD that minimizes discomfort or pain by avoiding such side effects [12].

Stress analysis can provide useful information to control MAD-induced discomfort and prevent occlusal or mandibular changes after long-term treatments. Finite element (FE) analysis is a mathematical method that uses computation to predict approximate values in a physical system that is highly susceptible to external factors. Recent studies have reported the use of FE analysis for dental braces, but such use for the evaluation of MAD-induced stress has yet to be explored [13,14]. Therefore, the purpose of this study was to propose a novel MAD design to distribute stress among the teeth and gingiva and to use FE analysis to show positive outcomes such as a reduced risk of occlusal change and relief from discomfort. To carry out the optimized design, FE analysis was adopted to analyze the modeled stress distribution between a conventional MAD and the newly proposed design.

\section{Materials and Methods}

\subsection{Proposal for a New Mandibular Advancement Device}

Figure 1a demonstrates a conventional MAD design consisting of upper and lower trays with an elastic strap connecting the two [15]. When a patient wears this device, the elastic strap obliquely connects the upper and lower trays, resulting in lower tray protrusion to prevent airway closure. Although conventional MADs have their merits, such as low cost and easy attachment, they tend to concentrate stress on the upper dentition. Because of this design, orthodontic side effects such as occlusal changes have been reported $[7,9,16]$. Furthermore, once the MAD is installed, the patient tends to feel discomfort because it does not allow even the slightest of movements. To resolve these disadvantages, we propose a new type of MAD (Figure 1b) that consists of new components for the upper tray: a supporting shield, which helps to distribute the stress along the upper dentition, and a protruding part to maintain the lower tray in the protruded position (Figure 2). In addition, the supporting shield made of a soft biocompatible material different from the hard tray materials serves to minimize damage to the upper gingiva. The trays are connected with several elastic springs through hooks (Figure 1b). Because the upper and lower trays are installed separately and then connected with springs, the patient is more likely to experience comfort during attachment and detachment. Furthermore, with the proposed MAD in place, the specially designed springs allow slight movements, providing more comfort and guaranteeing a superior compliance rate.
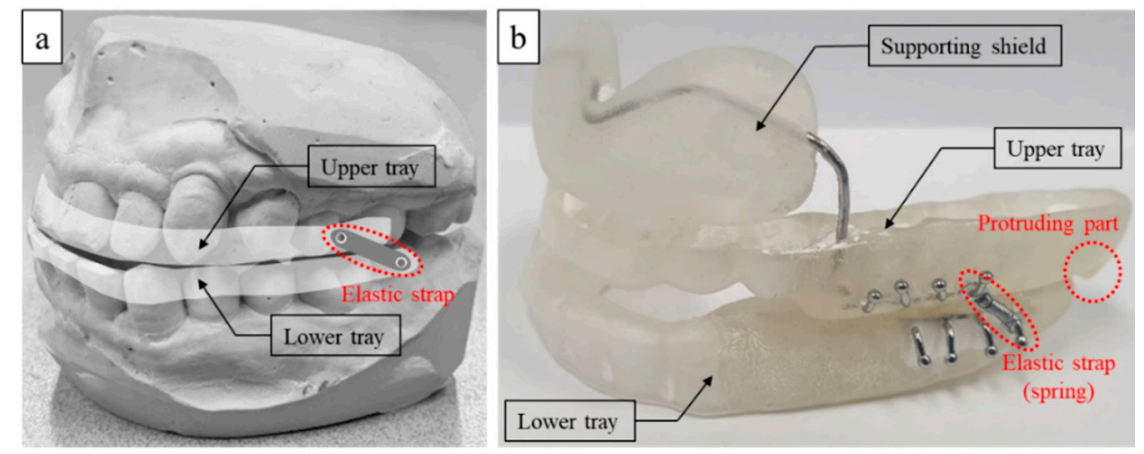

Figure 1. Mandibular advanced device (MAD): (a) conventional type and (b) prototype of the proposed MAD. 

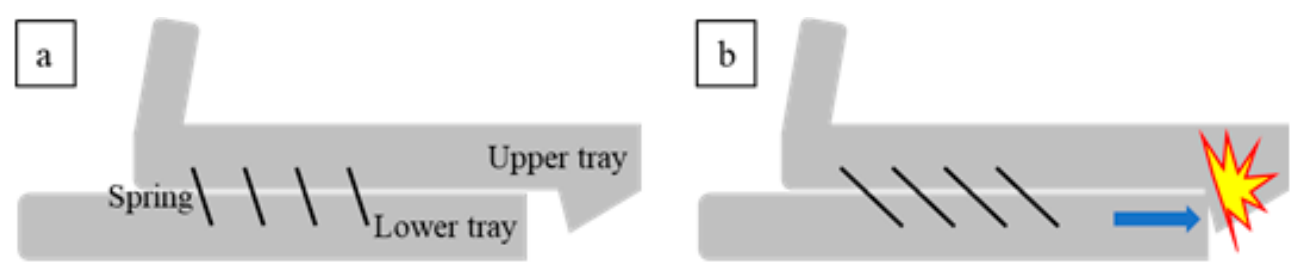

Figure 2. Mechanism of the proposed MAD: (a) initial state and (b) mechanism blocking protrusion.

\subsection{Finite Element Analysis for the Newly Proposed Mandibular Advancement Device}

To validate the stress distribution induced by the proposed MAD, FE analysis was conducted using the commercial FE package, ABAQUS/Explicit [17]. Based on laser scanning data, three-dimensional modeling for the upper dentition and MAD was conducted using HyperMesh (Figure 3a,b) [18]. The material properties of the upper dentition, including the gingival area, were assumed to have the average physical properties of teeth and gingiva, and the MAD was assumed to have the properties of standard plastic [19-21]. Table 1 summarizes the material properties for the FE analysis. Because the MAD is assumed to maintain the mandible at $60-70 \%$ of the maximal advancement position, the mandible protruded by the MAD is subjected to an external force for returning to the original position (Figure 3c) [22]. To analyze the stress at the upper tooth and gingival area caused by this external force, a force boundary condition of $2.5 \mathrm{~N}$ was applied along the Z-direction [23]. The FE analysis results between the conventional and the newly proposed MAD were compared in terms of stress distribution to ensure the effect of the supporting shield on the upper dentition and gingival area.
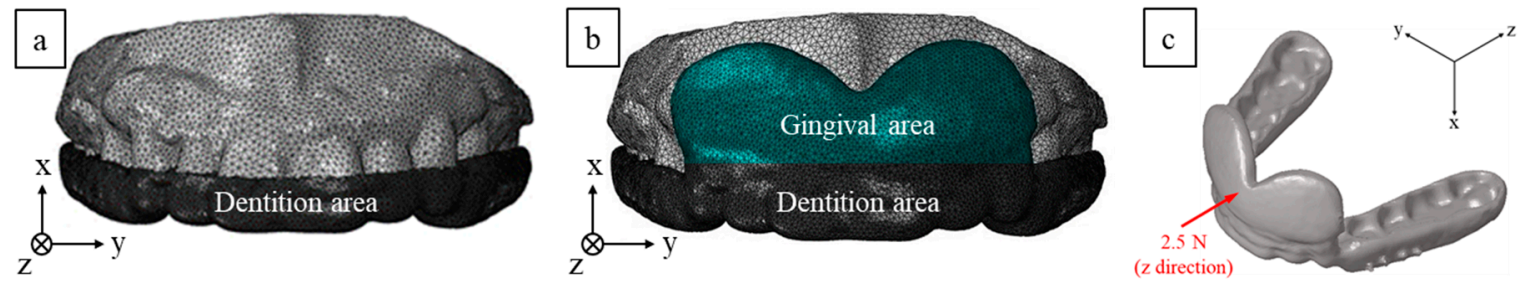

Figure 3. Finite element (FE) modeling of MAD with upper dentition: (a) conventional, (b) proposed, and (c) boundary condition.

Table 1. Material properties of MAD, upper dentition, and gingiva.

\begin{tabular}{ccccc}
\hline Part & Element Type & $\begin{array}{c}\text { Number of } \\
\text { Elements }\end{array}$ & $\begin{array}{c}\text { Young's Modulus } \\
\text { (MPa) }\end{array}$ & Poisson's Ratio \\
\hline MAD & Tetrahedron & 169,624 & 700,000 & 0.30 \\
Upper dentition & Tetrahedron & 38,660 & 18,000 & 0.30 \\
Gingiva & Tetrahedron & 130,964 & 9,009 & 0.03 \\
\hline
\end{tabular}

MAD: mandibular advancement device; MPa: megapascal, unit of pressure equal to $10^{6}$ pascals.

\section{Results}

The stress distribution of the FE analysis comparing the conventional and proposed MAD is shown in Figure 4. We used FE analysis based on four data points over the front teeth (a-d) and two data points over the gingiva (e and f) to compare the stress distribution (Figure 5). The mean stress and standard deviation of the proposed MAD were lower than in the conventional MAD. The stress level at points "a" to " $\mathrm{e}$ " in the proposed MAD decreased substantially to $17 \%$ from $53 \%$ in the conventional MAD. However, stress distribution induced by the proposed MAD around the gingival area increased to $173 \%$ compared with the conventional MAD at point " $\mathrm{f}$ " because the supporting shield tended to distribute the concentrated force to the gingival area (Table 2). 

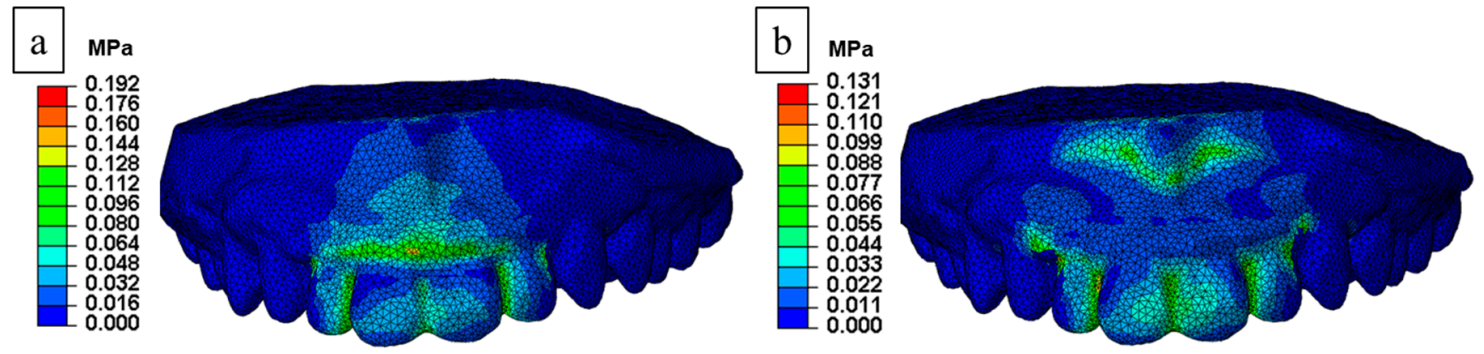

Figure 4. Stress distribution from FE analysis: (a) conventional and (b) proposed MAD.
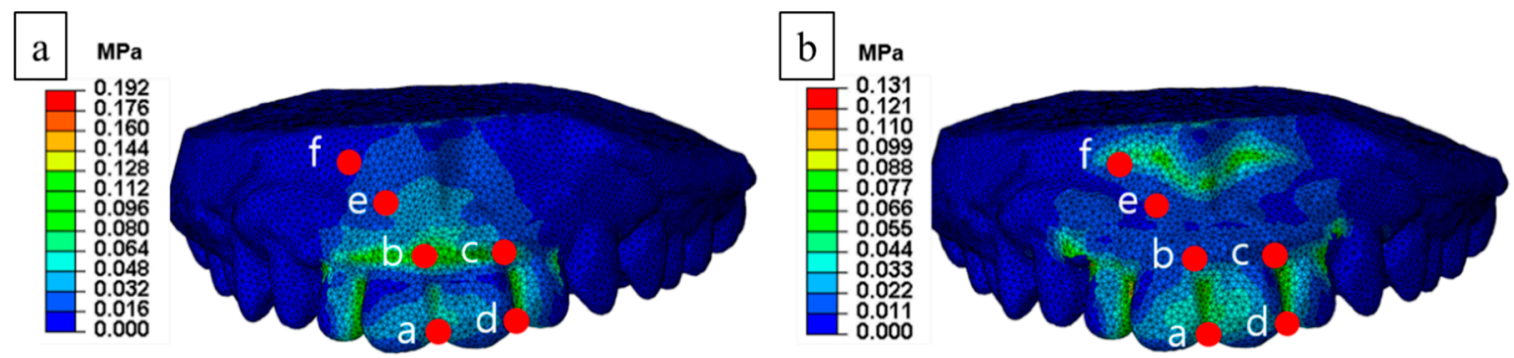

Figure 5. Comparative analyzed points of stress distribution: (a) conventional and (b) proposed MAD.

Table 2. Comparison of stresses between the conventional and proposed MAD.

\begin{tabular}{cccccccc}
\hline \multirow{2}{*}{ MAD } & \multicolumn{9}{c}{ Position (MPa) } & & Stress \\
\cline { 2 - 8 } & $\mathbf{a}$ & $\mathbf{b}$ & $\mathbf{c}$ & $\mathbf{d}$ & $\mathbf{e}$ & $\mathbf{f}$ & Mean \pm STD \\
\hline $\begin{array}{c}\text { Conventional } \\
\text { (Figure 5a) }\end{array}$ & 0.080 & 0.102 & 0.070 & 0.112 & 0.040 & 0.023 & $0.071 \pm 0.034$ \\
$\begin{array}{c}\text { Proposed } \\
\text { (Figure 5b) }\end{array}$ & 0.063 & 0.048 & 0.058 & 0.065 & 0.023 & 0.040 & $0.050 \pm 0.016$ \\
Proposed/Conventional & 0.79 & 0.47 & 0.83 & 0.58 & 0.58 & 1.73 & 0.70 \\
\hline
\end{tabular}

STD, standard deviation; MPa, megapascal; unit of pressure equal to $10^{6}$ pascals.

\section{Discussion}

Our proposed novel MAD design not only maintained a wide upper airway, but also controlled the induced force. The presence of a supporting shield in the newly proposed MAD produced a change in the contact area between the device and oral structures, causing a different stress distribution on the front teeth and gingival area. This was confirmed by FE analysis.

Factors that influence patient compliance with the use of an MAD include side effects such as discomfort, mouth dryness, gum irritation, excessive salivation, and pain. Additionally, side effects associated with occlusal changes, such as overjet, overbite, and incisor inclination in occlusion, have been reported for long-term use $[7,9,16]$. Larger forces produce larger occlusal changes, which progressively decrease the advancement of the lower jaw, resulting in a reduced therapeutic effect on SDB. In addition, excessive overstretching can adversely affect the shape of the soft tissue structures in the upper airway and the tension of the muscles involved [4]. A device that can minimize occlusal changes would lead to a reduced risk of having to keep the mandible continuously advanced [24]. A device that can be more easily adaptable with an appropriate anatomic fit would also provide more comfort to patients, resulting in increased compliance. FE analysis is an interpretation program that provides the researcher with flexibility in options. It can predict stress values and their distribution while handling external forces at any level. It also provides accurate analyses before and after specific modifications. In addition, there are no limitations to the materials that can be used for testing, which makes it more cost-effective and time-efficient than animal experiments $[13,14,25]$. FE analysis is used in the analysis and design of medical devices, including dental braces [13,14,26]. Moreover, the computational mechanobiological algorithms for developing a suitable and optimized design 
of medical devices are currently being tried in many clinical applications [26,27]. Here we have demonstrated that quantitative visual analysis can be applied to MADs using FE analysis and that there are advantages to this method. A novel simulation program using FE analysis and computational mechanobiological algorithms will be valuable in minimizing the side effects and developing advanced MADs for patients with skeletal deformities, such as a retrognathic mandible and constricted maxilla. Close collaboration between clinicians and mechanical engineers is essential. Our novel MAD design can enhance comfort in attachment and detachment because the upper and lower trays can be inserted separately, controlling tension through the springs. However, further studies including clinical trials are needed to confirm these points.

There were some limitations to our study because the force boundary conditions in the FE analysis applied to the upper tray were simplified in terms of patient anatomy, such as oral structure and the shape of the upper dentition. Simplifying the model could reduce the cost, but the conditions of analysis must be set carefully to consider these neglected parts. Additionally, this study restricted the movement of mandible to only anterior and posterior directions. Considering the diverse range of movement of the mandible, further studies are needed to measure the actual stress induced by wearing an MAD on the entire mouth, maxilla, mandible, and temporomandibular joint. In scanning for this study, we had difficulty distinguishing the upper dentition from the upper gingival area; therefore, we used the average physical properties for the dentin and gingiva as parts of the same structure. Further studies are needed to assess the stress on the dentition and gingiva separately. Advanced technologies such as three-dimensional printing will be possible to create more realistic models that reflect individual patient characteristics and complex head structures [27]. The relationship between the results of FE analysis and clinical side effects should also be verified in clinical studies. Despite these limitations, we hope that this study will facilitate further research into MAD design.

\section{Conclusions}

A proposed novel MAD design with a supporting shield reduced concentrated stress levels at the front teeth by distributing it into the gingival area, according to the FE analysis. Simulation models using biomechanics such as FE analysis, which help to evaluate differences in stress induced by different MAD devices, will be needed in the future to control or reduce the side effects of MADs such as occlusal change, discomfort, and pain.

Author Contributions: Conceptualization, J.Y., S.H.L. and D.-H.K.; Data curation, S.H.L. and S.Y.L.; Formal analysis, J.Y., Y.J. and H.-I.S.; Project administration, D.-H.K.; Validation, J.Y., S.H.L. and D.-H.K.; Writing一original draft, S.H.L. and D.-H.K.; Writing—review \& editing, J.Y., Y.J., D.-H.K., H.-I.S. and S.Y.L. All authors have read and agreed to the published version of the manuscript.

Funding: Support for this study was provided by the Alumni of Department of Otorhinolaryngology, the Catholic University of Korea, College of Medicine, and the Catholic Medical Center Research Foundation made in the program year of 2014 (grant number, 52016B000100026).

Conflicts of Interest: The authors declare no conflict of interest.

\section{References}

1. Asha'ari, Z.A.; Hasmoni, M.H.; Ab Rahman, J.; Yusof, R.A.; Lope Ahmad, R.A.R. The association between sleep apnea and young adults with hypertension. Laryngoscope 2012, 122, 2337-2342. [CrossRef] [PubMed]

2. Shahar, E.; Whitney, C.W.; Redline, S.; Lee, E.T.; Newman, A.B.; Nieto, F.J.; O'connor, G.T.; Boland, L.L.; Schwartz, J.E.; Samet, J.M. Sleep-disordered breathing and cardiovascular disease: Cross-sectional results of the Sleep Heart Health Study. Am. J. Respir. Crit. Care. Med. 2001, 163, 19-25. [CrossRef] [PubMed]

3. Clark, G.T.; Sohn, J.W.; Hong, C.N. Treating obstructive sleep apnea and snoring: Assessment of an anterior mandibular positioning device. J. Am. Dent. Assoc. 2000, 131, 765-771. [CrossRef] [PubMed] 
4. Cantore, S.; Ballini, A.; Farronato, D.; Malcangi, G.; Dipalma, G.; Assandri, F.; Garagiola, U.; Inchingolo, F.; de Vito, D.; Cirulli, N. Evaluation of an oral appliance in patients with mild to moderate obstructive sleep apnea syndrome intolerant to continuous positive airway pressure use: Preliminary results. Int. J. Immunopathol. Pharmacol. 2016, 29, 267-273. [CrossRef]

5. Mostafiz, W.R.; Carley, D.W.; Viana, M.G.C.; Ma, S.; Dalci, O.; Darendeliler, M.A.; Evans, C.A.; Kusnoto, B.; Masoud, A.; Galang-Boquiren, M.T.S. Changes in sleep and airway variables in patients with obstructive sleep apnea after mandibular advancement splint treatment. Am. J. Orthod. Dentofacial. Orthop. 2019, 155, 498-508. [CrossRef]

6. Ng, A.T.; Gotsopoulos, H.; Qian, J.; Cistulli, P.A. Effect of oral appliance therapy on upper airway collapsibility in obstructive sleep apnea. Am. J. Respir. Crit. Care. Med. 2003, 168, 238-241. [CrossRef] [PubMed]

7. de Almeida, F.R.; Lowe, A.A.; Tsuiki, S.; Otsuka, R.; Wong, M.; Fastlicht, S.; Ryan, F. Long-term compliance and side effects of oral appliances used for the treatment of snoring and obstructive sleep apnea syndrome. J. Clin. Sleep. Med. 2005, 1, 143-152. [PubMed]

8. McGown, A.D.; Makker, H.K.; Battagel, J.M.; L'Estrange, P.R.; Grant, H.R.; Spiro, S.G. Long-term use of mandibular advancement splints for snoring and obstructive sleep apnoea: A questionnaire survey. Eur. Respir. J. 2001, 17, 462-466. [CrossRef]

9. Bartolucci, M.L.; Bortolotti, F.; Martina, S.; Corazza, G.; Michelotti, A.; Alessandri-Bonetti, G. Dental and skeletal long-term side effects of mandibular advancement devices in obstructive sleep apnea patients: A systematic review with meta-regression analysis. Eur. J. Orthod. 2019, 41, 89-100. [CrossRef]

10. Patel, S.; Rinchuse, D.; Zullo, T.; Rekha, W. Long-term dental and skeletal effects of mandibular advancement devices in adults with obstructive sleep apnoea: A systematic review. Int. Orthod. 2019, 17, 3-11. [CrossRef]

11. Vigie du Cayla, G.; Collet, J.M.; Attali, V.; Kerbrat, J.B.; Benslama, L.; Goudot, P. Long-term effectiveness and side effects of mandibular advancement devices on dental and skeletal parameters. J. Stomatol. Oral. Maxillofac. Surg. 2019, 120, 7-10. [CrossRef] [PubMed]

12. Vanderveken, O.M.; Van de Heyning, P.; Braem, M.J. Retention of mandibular advancement devices in the treatment of obstructive sleep apnea: An in vitro pilot study. Sleep Breath 2014, 18, 313-318. [CrossRef] [PubMed]

13. Vasquez, M.; Calao, E.; Becerra, F.; Jorge, O.; Carlos, E.; Eliseo, F. Initial stress differences between sliding and sectional mechanics with an endosseous implant as anchorage: A 3-dimensional finite element analysis. Angle Orthod. 2001, 71, 247-256. [PubMed]

14. Cattaneo, P.M.; Dalstra, M.; Melsen, B. Moment-to-force ratio; center of rotation; and force level: A finite element study predicting their interdependency for simulated orthodontic loading regimens. Am. J. Orthod. Dentofacial. Orthop. 2008, 133, 681-689. [CrossRef]

15. Henke, K.G.; Frantz, D.E.; Kuna, S.T. An oral elastic mandibular advancement device for obstructive sleep apnea. Am. J. Respir. Crit. Care. Med. 2000, 161, 420-425. [CrossRef]

16. Marklund, M. Predictors of long-term orthodontic side effects from mandibular advancement devices in patients with snoring and obstructive sleep apnea. Am. J. Orthod. Dentofacial. Orthop. 2006, 129, $214-221$. [CrossRef]

17. ABAQUS Unified FEA. Dassault Systems. Available online: https://www.3ds.com/products-services/simulia/ products/abaqus/ (accessed on 24 December 2019).

18. Altair Hypermesh. Altair. Available online: https://www.altair.com/hypermesh/ (accessed on 24 December 2019).

19. Goktas, S.; Dmytryk, J.J.; McFetridge, P.S. Biomechanical behavior of oral soft tissues. J. Periodontol. 2011, 82, 1178-1186. [CrossRef]

20. Hayasaki, H.; Okamoto, A.; Iwase, Y.; Yamasaki, Y.; Nakataet, M. Occlusal contact area of mandibular teeth during lateral excursion. Int. J. Prosthodont. 2004, 17, 72-76.

21. He, L.H.; Swain, M.V. Understanding the mechanical behaviour of human enamel from its structural and compositional characteristics. J. Mech. Behav. Biomed. Mater. 2008, 1, 18-29. [CrossRef]

22. Gong, X.; Zhang, J.; Zhao, Y.; Gao, X. Long-term therapeutic efficacy of oral appliances in treatment of obstructive sleep apnea-hypopnea syndrome. Angle Orthod. 2013, 83, 653-658. [CrossRef]

23. Gjessing, P. Biomechanical design and clinical evaluation of a new canine-retraction spring. Am. J. Orthod. 1985, 87, 353-362. [CrossRef] 
24. Lee, J.S.; Choi, H.I.; Lee, H.; Ahn, S.J.; Noh, G. Biomechanical effect of mandibular advancement device with different protrusion positions for treatment of obstructive sleep apnoea on tooth and facial bone: A finite element study. J. Oral. Rehabil. 2018, 45, 948-958. [CrossRef] [PubMed]

25. Savonnet, L.; Wang, X.; Duprey, S. Finite element models of the thigh-buttock complex for assessing static sitting discomfort and pressure sore risk: A literature review. Comput. Methods Biomech. Biomed. Eng. 2018, 21, 379-388. [CrossRef] [PubMed]

26. Boccaccio, A.; Ballini, A.; Pappalettere, C.; Tullo, D.; Cantore, S.; Desiate, A. Finite element method (FEM), mechanobiology and biomimetic scaffolds in bone tissue engineering. Int. J. Biol. Sci. 2011, 7, 112-132. [CrossRef] [PubMed]

27. Boccaccio, A.; Uva, A.E.; Fiorentino, M.; Monno, G.; Ballini, A.; Desiate, A. Optimal Load for Bone Tissue Scaffolds with an Assigned Geometry. Int. J. Med. Sci. 2018, 15, 16-22. [CrossRef] [PubMed]

(C) 2020 by the authors. Licensee MDPI, Basel, Switzerland. This article is an open access article distributed under the terms and conditions of the Creative Commons Attribution (CC BY) license (http://creativecommons.org/licenses/by/4.0/). 